MATEC Web of Conferences 47, 05007 (2016)

DOI: $10.1051 /$ matecconf/20164705007

(C) Owned by the authors, published by EDP Sciences. 2016

\title{
The Growth of Aspergillus Niger on a Wood Based Material with 4 Types of Wall Finishing
}

\author{
Menega Subramaniam ${ }^{1, a}$, Norshuhaila Mohamed Sunar ${ }^{2}$, Adnan Latif ${ }^{1}$, Umi Kalthsom Parjo ${ }^{2}$, Chin \\ Ming $\mathrm{Er}^{1}$ and Abdul Rafiq Ab Razak ${ }^{1}$ \\ ${ }^{1}$ Faculty of Civil and Environmental Engineering, Universiti Tun Hussein Onn Malaysia, 86400 Batu Pahat, Johor, \\ Malaysia \\ ${ }^{2}$ Faculty of Engineering Technology, Universiti Tun Hussein Onn Malaysia, 86400 Batu Pahat, Johor, Malaysia
}

\begin{abstract}
Buildings are a vital component in a human's daily life. It provides shelter from the environment, weather and animals. Mold growth within the building might be caused by the moisture problems which directly act on it such as water leaks or indirect factor such as high humidity levels. This growth causes esthetic problems and deterioration of its wall coatings. Spores from the fungi also cause health problems to humans. The fungus species studied in this research is Aspergillus niger. The material is made of wood and its finishing is thick wallpaper, thin wallpaper, acrylic paint and glycerol based paint. ASTMD5590-00 standard was used to evaluate fungal growth and to determine if non antifungal agent was effective in inhibiting the amount of fungal growth on four types of wall finishing used on wooden walls. This research was conducted without using any antifungal agent. Highest percentage of growth of the fungi was found on acrylic paint, followed by glycerol based paint and thin wallpaper. Thick wall paper shows the least growth of fungi. The maximum growth is visible on day 12 which is more than $60 \%$ by all the wall finishing.
\end{abstract}

\section{Introduction}

Mold causes significant problems when it comes to aesthetic value within a building. It may lead to surface problems such as degradation and spalling. Fungi are organisms that colonize on building coatings and thrive on them $[1,2]$. Using wood as the building material is also the main cause of mold and fungi colonization in buildings. Controls on the pollutant sources are considered because the design, efficiency and economics of the IAQ control can be influenced [3]. Most people work in an office environment [4]. This is an area where a hazard such as chemicals, lighting and indoor air quality rises. Health problems such as asthma, irritations and other issues are spread due to airborne fungal spore which effect humans drastically [5-7]. These signs are uncommon in buildings that are well maintained but water leaks and inappropriate humidity levels causes high fungal spore loads $[8,9]$. A fungus is able to grow almost on all natural and synthetic materials especially if they are wet $[10,11]$. Wood is vulnerable to fungal attack [12]. Kiln dried wood surfaces are more susceptible to fungi infection compared to other wood types [13]. Acylated wooden furniture's, wood polyethylene composites, plywood and modified wood products are susceptible to infestation by Aspergillus, Trichoderma and Penicillium. Paper and glue used on indoor surfaces are very good growth substrates

${ }^{\text {a }}$ Corresponding author : menegasubramaniam@gmail.com 
for most of the indoor fungi as they provide a wet environment for the fungi. Aspergillus and Penicillium grow superficially on painted surfaces, but Aureobasidiumpullulans was found to deteriorate the paints. Acrylic painted surfaces are attacked by Alternaria, Cladosporium, and Aspergillus. There are 3 main factors that influence the growth of fungi in buildings. They are moisture, nutrients and temperature [14]. Material types and humidity are also factors that control the fungi growth in structures. Material such as gypsum board, wallpaper, mortar and paint are common in the construction industry. Aspergillus species are commonly found on ceramic-type materials (concrete, mortar) and paints and glues. Cellulose based materials are much sensitive to contamination by fungi compared to inorganic materials such as gypsum, mortar and concrete. Cellulose can be metabolized by the microorganisms [15]. A large variety of construction materials are sensitive to the development of mold. Nevertheless, it seems clear that the materials/substrate does influence the type of mould that develops on the surface. A few studies have demonstrated that the fungal genera detected on construction plaster are predominantly Penicillium or Aspergillus [16]. Studies have shown materials with strong concentrations of organic carbon like cellulose or carbonates (wall paper, wood-based building materials) are more favourable to the development of mould than those with lower carbon content (plaster, glass wool) [16]. Thus the objective of this study is to determine the effectiveness of different wall finishing (thick wallpaper, thin wallpaper, glycerol based paint and acrylic paint) on wood based material to reduce the growth of Aspergillus niger without applying any type of antifungal agent.

\section{Materials and Methods}

\subsection{Preparation of bio-resistance test}

The wall finishing which is the acrylic paint (AP), glycerol based-paint (GBP), thin wall paper (TnW) and thick wallpaper (TkW) are used to cover the supports (woods). The weight of the thick wall paper is $240 \mathrm{~g} / \mathrm{m}^{2}$ and the thin wall paper is $80 \mathrm{~g} / \mathrm{m}^{2}$. According to Vacher et al. [16] the supports (woods) were cut into samples size of $50 \mathrm{~mm} \times 50 \mathrm{~mm}$. Then, $70 \%$ of ethanol was used to wash each surface of the samples. The samples were left to dry for a few hours. After drying was completed, the acrylic paint and the glycerol based paint were each applied on different surface of wood samples to cover the wood. The thin and thick wall paper was glued on the surface of the supports. Approximately 24 to 48 hours were taken to dry the samples. Next, the fungal spores were inoculated. The samples are proceeded to test in a germicide UV-lamp for 40 minutes before the samples were kept in individual dishes. $50 \mu \mathrm{l}$ of the fungus spore suspension was applied on top of the wall finishing. Finally, the petri dish was sealed using parafilm. The samples were placed into the incubator for 27 days for observation. Relative humidity (RH) was set up to $55 \% \pm 2 \%$ and the temperature at $28^{\circ} \mathrm{C} \pm 1{ }^{\circ} \mathrm{C}$ as stated in ASTM D5590-00 Guidelines [17]. Regular observations were done for 3, 6, 9, 12, 15, 18, 21, 24 , and 27 days for each test at the same time.

\subsection{Measurement of result}

American Society for Testing and Materials (ASTM) D5590-00 Standard Scale was referred for analyzing the data [17]. The analyzing of the data was carried out for the free-antifungal substrate and consists of different wall finishing cover surface. As the result, the efficiency of the various wall finishing in treating the indoor fungal is observed by the rate of the fungal growth (at $27^{\text {th }}$ days). For observation, the decrease rate of mold growth on the supports, graph of fungal growth versus four types of wall finishing are plotted. These graphs can show the reduction in rate of indoor fungi on the support. The measurement also includes the percentage of fungi growth and the diameter of the fungi. 
Table 1. Scale for evaluation fungal growth (ASTM D5590-00 Standard Scale).

\begin{tabular}{|l|l|l|}
\hline Scale & Percentage of Fungi Growth & Degree of Fungi Growth \\
\hline 0 & 0 & None trace of growth \\
\hline 1 & $(<10 \%)$ & Trace Growth \\
\hline 2 & $(10-30 \%)$ & Light growth \\
\hline 3 & $(30-60 \%)$ & Moderate growth \\
\hline 4 & $(60-100 \%)$ & Heavy growth \\
\hline
\end{tabular}

Three graphs are tabulated according to percentage of fungi growth, rating scale and also the diameter of fungi growth.

\section{Results and Discussion}

The growth of fungi on different wall finishing which is not treated with any type of antifungal agent was shown (Figure 1). Acrylic paint (AP) and glycerol based paint (GBP) have higher percentage of fungi growth compared to thick wallpapers $(\mathrm{TkW})$ and thin wallpapers $(\mathrm{TnW})$. The highest percentage of fungi growth was by AP which reached its maximum by day 12 at $100 \%$. This shows that AP and GBP is unsuitable as wall finishing on wood unless it was treated or applied with a layer of antifungal [13]. The least growth of fungi was found on control sample which was the TkW. It took almost 27 days to reach $90 \%$ compared to other types of wall finishing. The thickness of the wall finishing influences the growth of the fungi. Method is as shown above.

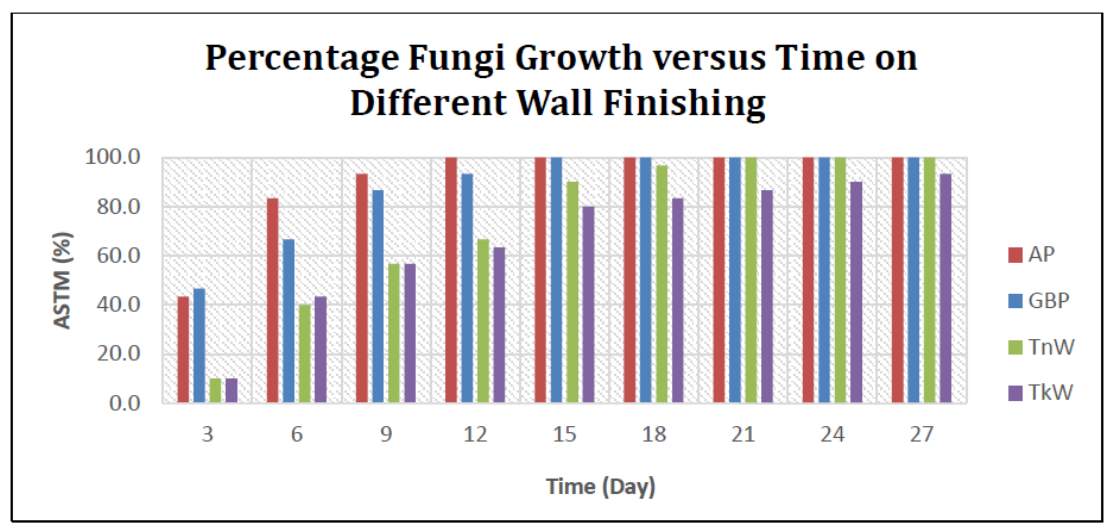

Figure 1. Percentage of fungi growth on different wall finishing without antifungal agent.

The Rating Scale for control sample that is sample without antifungal agent was shown (Figure 2). On day 3 as the first reading, acrylic paint shows the highest rating on fungi growth. It reached rating as 2.6 followed by 2.4 by glycerol based paint. Both wall papers had the same rating on day 3 which is 1.0. Indoor fungal growth of this sample increased drastically until Day 15 then remained stable where all of them reached 4.0 rating scale.

The diameter of fungi growth on different types of wall finishing is as shown (Figure 3). The highest diameter of fungi recorded on day 3 was the sample with acrylic paint. It was $2.5 \mathrm{~cm}$ of fungi formed on acrylic paint as wall finishing on wood. The minimum diameter at day 3 was stated on thick wallpaper. It is proved that in this study, wallpapers also as equal as the paints on fungi growth beyond day 18. Thick wallpaper is more effective to resist fungal growth compared to 
thin wallpaper. This might be due to the difference in thickness of wallpaper that can prevent the spore from getting the nutrient from the agar.

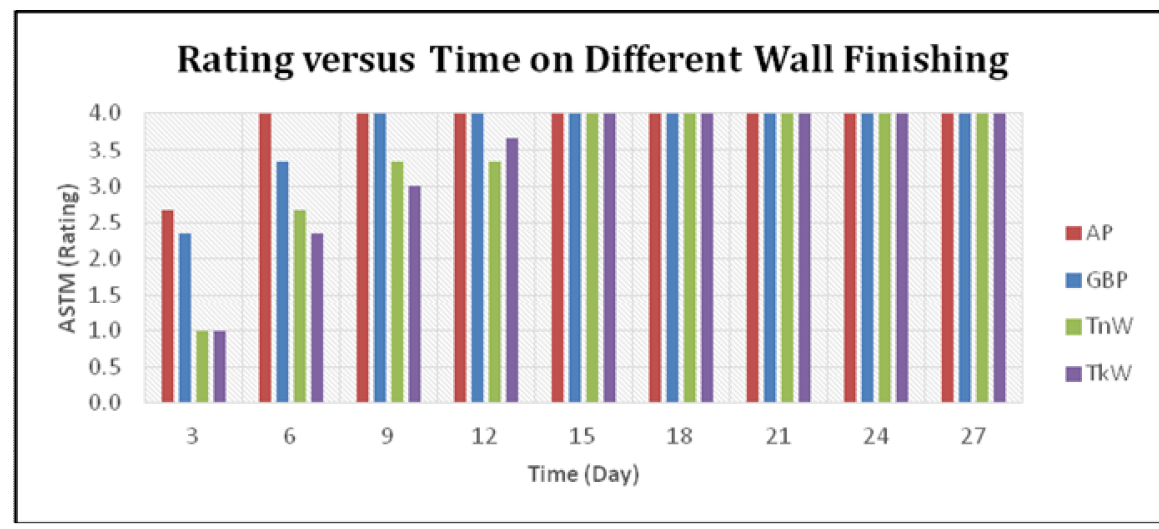

Figure 2. Rating scale versus time on different wall finishing without antifungal agent.

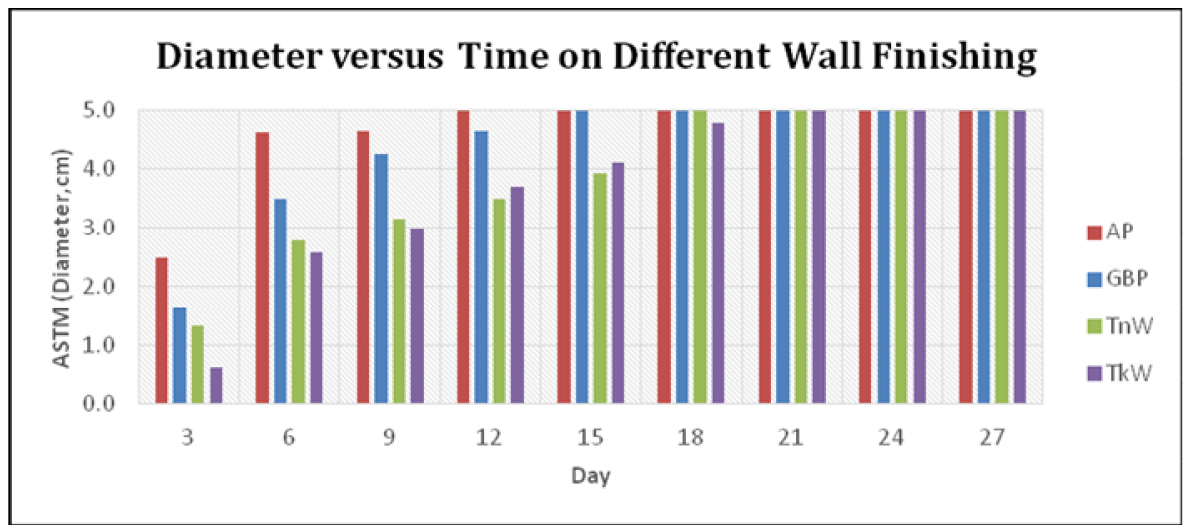

Figure 3. Diameter of fungi growth versus time.

\section{Conclusions}

The fastest growth of Aspergillus niger on wood based material with 4 types of wall finishing was found on acrylic paint, followed by glycerol based paint and thin wallpaper. The slowest fungi growth for the sample was found on thick wallpaper. It is suggested that antifungal agent should be added to avoid indoor fungi growth and to act as a protective layer for the wall finishing.

\section{Acknowledgements}

The authors would like to acknowledge Research and Innovation Centre (R\&D) Research, Innovation, Commercialization \& Consultancy Office (ORICC) Universiti Tun Hussein Onn Malaysia for funding this project under grant FRGS vot 1479. 


\section{References}

[1] N. Bellotti, L. Salvatore, C. Deyá, M.T. Del Panno, B. del Amo and R. Romagnoli, The application of bioactive compounds from the food industry to control mold growth in indoor waterborne coatings, Colloids Surf. B. Biointerfaces, 104, 140-144, (2013).

[2] C.M. Er, N.M. Sunar, A.M. Leman and N. Othman, Direct growth inhibition assay of total airborne fungi with application of biocide-treated malt extract agar, MethodsX, 2, 340-344, (2015).

[3] S. Lee, G. Kwon, J. Joo, J.T. Kim and S. Kim, A finish material management system for indoor air quality of apartment buildings (FinIAQ), Energy and Buildings, 46, 68-79, 2012.

[4] C.M. Er, N.M. Sunar, A.M. Leman and O. Norzila, Evaluation of potassium sorbate as a biocide to reduce viability of total airborne fungi in a higher educational building of computer studies, J. of Advanced Research in Materials Science, 2(1), 15-19, (2014).

[5] C.M. Er, N.M. Sunar A.M. Leman, N. Othman, Q. Emparan, U.K. Parjo, P. Gani, N.A. Jamal and N.A. Ideris, The evaluation of indoor microbial air quality in two new commissioning higher educational buildings in Johor, Malaysia, Applied Mechanics and Materials, 774, 1068-1072, (2015).

[6] J.A. Crawford, P.F. Rosenbaum, S.E. Anagnost, A. Hunt and J.L. Abraham, Indicators of airborne fungal concentrations in urban homes: Understanding the conditions that affect indoor fungal exposures, Sci. Total Environ., 517, 113-124, (2015).

[7] C.M. Er, N.M. Sunar, A.M. Leman, N. Othman, U. Kalthsom, N.A. Jamal and N.A. Ideris, The biocidal effect of potassium sorbate for indoor airborne fungi remediation, Desalin. Water Treat., 57(1), 1-6, (2015).

[8] U.K. Parjo, N.M. Sunar, A.M. Leman, N.A. Ideris, P. Gani, Q. Emparan and C.M. Er, Indoor fungal treatment by using potassium sorbate as bio-resistance coating for different plasterboard wall finishings, Applied Mechanics and Materials, 774, 1116-1120, (2015).

[9] K. Parjo, N.M. Sunar, A.M. Leman and C.M. Er, Effect of fungal growth on the surface of painted plasterboards, Advances in Environmental Biology, 9(20), 15-19, (2015).

[10] C.M. Er, N.M. Sunar, A.M. Leman, N. Othman, P. Gani, N.A. Jamal, Q.A. Emparan and U.K. Parjo, In vitro inhibitory assay of an isolated indoor airborne fungus from an institutional building of computer education by using potassium sorbate, Applied Mechanics and Materials, 774, 10911095, (2015).

[11]X. Zhang, B. Sahlberg, G. Wieslander, C. Janson, T. Gislason and D. Norback, Dampness and moulds in workplace buildings: Associations with incidence and remission of sick building syndrome (SBS) and biomarkers of inflammation in a 10year follow-up study, Sci. Total Environ., 430, 75-81, (2012).

[12] G. Ayanbimpe, W. Danjuma and M. Okolo, Relationship between fungal contamination of indoor air and health problems of some residents in Jos, InTech, 1-19, (2003).

[13]C.A. Clausen and V.W. Yang, Multi-component biocide protects wood from fungi and insects in UC2 applications, American Wood Protection Association, 91, 31-35, (1998).

[14]U.K. Parjo, N.M. Sunar, A.M. Leman, P. Gani, Q. Emparan and C.M. Er, Coating bio-resistance test of different wall finishing for isolated indoor fungal treatment by using potassium sorbate biocide on wood, Applied Mechanics and Materials, 774(2), 1384-1388, (2015).

[15]T. Verdier, M. Coutand, A. Bertron and C. Roques, A review of indoor microbial growth across building materials and sampling and analysis methods, Build. Environ., 80, 136-149, (2014).

[16] S. Vacher, C. Hernandez, C. Bärtschi and N. Poussereau, Impact of paint and wall-paper on mould growth on plasterboards and aluminum, Build. Environ., 45(4), 916-921, (2010).

[17]ASTM ASTM D5590-00, Standard Test Method for Determining the Resistance of Paint Films and Related Coatings to Algal Defacement, ASTM International, (2013). 